\title{
mGlu5 receptor antagonist blocks bromocriptine-induced conditioned place preference in bilateral mesolimbic-lesioned rat
}

\author{
Omar Ouachikh ${ }^{a}$, Carine Chassain ${ }^{\mathrm{a}, \mathrm{b}}$, Guilhem Pagès ${ }^{\mathrm{c}}$, Franck Durif ${ }^{\mathrm{a}, \mathrm{b}}$, Aziz Hafidi ${ }^{\mathrm{a}, *}$ \\ a Clermont Université, Université d'Auvergne, EA7280, Laboratoire de Neuropsychopharmacologie des systèmes dopaminergiques sous corticaux, \\ Clermont-Ferrand, France \\ b CHU Clermont-Ferrand, Service de Neurologie, 63000 Clermont-Ferrand, France \\ ' 2 NMR platform “AgroResonance”, UR370 Qualité des produits animaux (QuaPA), INRA-Centre, Auvergne-Rhône-Alpes, 63122 Saint-Genès Champanelle, \\ France
}

\section{H I G H L I G H T S}

- Dopamine replacement therapy induces dopamine dysregulation syndrome in PD patients by sensitizing the pVTA-NAc pathway.

- Dopamine receptor agonist bromocriptine induces a positive reinforcement in bilateral pVTA-lesioned rats.

- This reinforcement is due to the activation of mGluR5. This receptor and glutamate are over expressed in the NAc shell of pVTA-lesioned rats.

- Antagonizing mGluR5 blocked the conditioned place preference expression and acquisition in pVTA-lesioned rats.

- Bromocriptine-induced reinforcement is due to the activation of the mGluR5 pathway in the NAc of pVTA-lesioned rats.

\section{A R T I C L E I N F O}

\section{Article history:}

Received 24 May 2016

Received in revised form 6 September 2016

Accepted 11 September 2016

Available online 13 September 2016

\section{Keywords:}

Conditioned place preference

6-OHDA

Parkinson

Reward

\begin{abstract}
A B S T R A C T
Dopamine dysregulation syndrome (DDS) has been attributed to both dopamine replacement therapies (DRT) and the mesencephalic dopaminergic lesion. The DRT reinforcement effect is due to its action on the reward system, particularly on the nucleus accumbens (NAc). This nucleus receives two major projections, a glutamatergic from the prefrontal cortex and a dopaminergic from the posterior ventral tegmental area (pVTA). The latter modulate the former within the NAc. pVTA has been demonstrated to be implicated in the motivational effect of bromocriptine (dopamine 2 receptor (D2R) agonist) in bilateral pVTA-lesioned animals. Therefore the potential implication of the metabotropic glutamate receptor 5 (mGluR5) antagonist (MTEP: 3-((2-Methyl-1,3-thiazol-4-yl)ethynyl)pyridine) on bromocriptine-induced conditioned place preference (CPP) was explored. Results showed that the administration of the MTEP blocked completely the bromocriptine-induced CPP in bilateral pVTA-lesioned rats. Both the CPP acquisition and expression were abolished. These effects are due, at least to an increase of the glutamate concentration and that of mGlu5 receptor expression in the NAc shell of the pVTA-lesioned animals. Altogether these data demonstrated the importance of the mGlu5 receptor in the bromocriptine inducedreinforcement and that DDS is probably due to DRT effect on this glutamate receptor.
\end{abstract}

(C) 2016 Published by Elsevier B.V.

\section{Introduction}

Parkinson's disease (PD) is characterized by a progressive loss of dopamine (DA) producing neurons which leads to motor disabilities (rigidity, akinesia, rest tremor and postural abnormalities), cognitive and vegetative disturbances [3,42]. Pharmacological therapies [26] rely mainly on dopamine replacement therapy (DRT), which consists of restoring the central DA transmission by

\footnotetext{
* Corresponding author.

E-mail address: azhafidi@univ-bpclermont.fr (A. Hafidi).
}

providing the DA precursor L-3,4-dihydroxyphenylalanine ( $\mathrm{L}$ dopa), and/or by using dopamine receptor agonists. DRT acts positively by partially restoring the motor function by activating the motor dorso-striatal pathway. However, DRT has negative side effects like its potential capacity to induce impulse control disorders such as pathological gambling, hypersexuality, compulsive shopping, punding, compulsive eating behaviors, and dopamine dysregulation syndrome (DDS) $[12,13,49]$, with a prevalence ranging from $14 \%$ to $43 \%[46,49,50]$. These DRT side effects are mostly due to the activation of the dopaminergic mesolimbic pathway originating from the posterior ventral tegmental area (pVTA). This nucleus is also affected by the dopaminergic degenerative 
process in Parkinson's disease [16]. Animal studies have indicated that pVTA dopaminergic projections to the nucleus accumbens (NAc) are crucial in drugs tolerance/dependence [24,30]. The NAc or the meso-accumbens pathway (pVTA to NAc) is particularly important for the development of the behavioral sensitization induced by stimulants and drugs of abuse [25]. The implication of the pVTA in DA receptor agonist's motivational process has been demonstrated previously $[39,40]$. The NAc dopaminergic denervation constitutes a preliminary condition for DA receptor agonists to induce a hedonistic effect in rats $[39,40]$. D2R agonists were able to induce a conditioned place preference (CPP) in pVTAlesioned rat [39] and this effect was attributed to an overexpression of D2R in the NAc shell [39]. Besides dopamine, the NAc also receives important glutamatergic projections from different cerebral structures such as the prefrontal cortex (PFC), the amygdala, the hippocampus and the thalamus [24]. DA modulates excitatory glutamatergic transmission within the NAc [18]. Both ionotropic and metabotropic glutamate receptors are involved in addictive behaviors [18]. More recently, different reports have highlighted the importance of the metabotropic glutamate receptor 5 in addiction [41]. mGlu5 receptor antagonists also ameliorate the motor alterations in parkinsonian animal models $[3,42]$.

Although VTA-NAc projection is involved in psychomotor and incentive sensitization, alterations in glutamatergic transmission within the NAc play important roles [18]. Drug exposure increases glutamatergic inputs to NAc contributing to cue-triggered drugseeking behavior [18]. The aim of our study was to investigate the role of mGlu5 receptor in the reinforcement, using the CPP paradigm, in bilateral pVTA-lesioned rats that have been previously sensitized with bromocriptine [39]. To this goal, a high specific mGlu5 receptor negative allosteric modulator 3-[(2-methyl-1,3thiazol-4-yl)ethynyl]pyridine (MTEP) which crosses the blood brain barrier [2] was used. In addition, both the expression of mGlu5 receptor and that of glutamate concentration were explored in the NAc.

\section{Materials and methods}

\subsection{Animals}

A total of 60 adult male Sprague-Dawley rats (180-210g) were obtained from Charles River (L'Arbresle, France) and maintained in a controlled environment (lights on 07:00-19:00, $22^{\circ} \mathrm{C}$ ) with food and water freely available. They were housed 4 per cage. The experiments followed the ethical guidelines of the International Association for the Study of Pain and the European Community Council directive and that of the animal ethical committee of the Clermont-University. All efforts were made to minimize the number of animals used.

\subsection{Experimental protocol}

Surgery was performed one week after animal arrival. Two weeks after surgery and before the CPP test, the locomotor tests and the mGlu5 receptor immunohistochemistry were performed. After the CPP test the rats were sacrificed and TH immunohistochemistry was performed to analyze the impact of the 6-OHDA on neuronal degeneration in the VTA.

\subsection{Drugs}

\begin{tabular}{|c|c|c|c|c|}
\hline Drug & Company & $\begin{array}{l}\text { Concentration/ } \\
\text { dose }\end{array}$ & administration & $\begin{array}{l}\text { Time to } \\
\text { CPP }\end{array}$ \\
\hline Bromocriptine & $\begin{array}{l}\text { Sigma-aldrich } \\
\text { (France) }\end{array}$ & $1 \mathrm{mg} / \mathrm{Kg}$ & Intra-peritoneal & $60 \mathrm{~min}$ \\
\hline MTEP & Tocris (France) & $3 \mathrm{mg} / \mathrm{Kg}$ & Intra-peritoneal & $30 \mathrm{~min}$ \\
\hline 6-OHDA & Tocris (France) & $6 \mu \mathrm{g} / \mu \mathrm{l}$ & Intracranial & \\
\hline
\end{tabular}

All drugs were received as powder from manufacturers. They were dissolved in $0.9 \%$ saline and/or DMSO at corresponding dose before use.

\subsection{Surgery}

Surgery was performed one week after animal arrival. Rats were divided to two groups:

1. pVTA-lesioned animals received bilateral injection of $1 \mu \mathrm{L} 6$ OHDA solution $(6 \mu \mathrm{g} / \mu \mathrm{L}$, dissolved in its vehicle $0.02 \%$ ascorbic acid in $0.9 \%$ saline) into the posterior VTA.

2. Sham group received bilateral injection of the vehicle.

In order to preserve noradrenergic neurons from 6-OHDA toxicity, animals received desipramine $(25 \mathrm{mg} / \mathrm{kg}$, i.p., Sigma-Aldrich, France) $30 \mathrm{~min}$ prior to the toxin injection [39,40]. After being anesthetized with i.p injection of ketamine $(75 \mathrm{mg} / \mathrm{kg})$ and xylazine $(50 \mathrm{mg} / \mathrm{kg})$ each rat was placed in a stereotaxic apparatus and the neurotoxin or the vehicle was injected bilaterally into the pVTA. The injection velocity was $0.1 \mu \mathrm{L} / \mathrm{min}$ using a $5 \mu \mathrm{L}$ Hamilton syringe. At the end of each injection the tip of the micropipette was rested in place for additional $5 \mathrm{~min}$. The coordinates of the bilateral injection sites were as follows: $-5.8 \mathrm{~mm}$ caudal to bregma, $\pm 0.6 \mathrm{~mm}$ from the midline and $-8.2 \mathrm{~mm}$ below the brain surface according to Paxinos and Watson's brain map.

The duration of the post-surgery recovery period was the same in all rats.

\subsection{Locomotors impairment}

\subsubsection{Y-maze task}

We used The Y-maze paradigm to assess short-term spatial memory which is based on the innate preference of animals to explore areas that have not been previously explored. The Y-maze apparatus consisted of three arms $(45 \mathrm{~cm}$ long, $10 \mathrm{~cm}$ wide and $20 \mathrm{~cm}$ high). After acclimatization, rats were placed individually at the end of an arm and allowed to enter the maze freely for a 5-min test session. Rats were tested once only. An arm entry was defined as the entry of all four paws one arm. The sequence of arm entries was recorded. Positive alternations are the number of three consecutive entries into three different arms $(A, B, C)$ such as $A B C, B C A$, and $C A B$. Then we calculate the score of alternation $Z=X / Y$, when $X$ is the number of positive alternations and $Y$ the number of total alternation. The results are presented as the means \pm SEM.

\subsubsection{Cylinder-test}

To assess spontaneous vertical activity "rearing", rats were placed in a standard glass beaker (transparent cylinder: $20 \mathrm{~cm}$ diameter and $30 \mathrm{~cm}$ height, Bioseb) with video monitoring from the side for a total of $5 \mathrm{~min}$. The number of full extension rears was manually scored post hoc by observer blind to treatment. The beaker was cleaned after each animal.

\subsection{Measurement of conditioned place preference}

\subsubsection{Place conditioning apparatus}

CPP experiments [23] were performed in three identical boxes (Imetronic, Pessac, France) formed by two lateral chambers $(15 \times 15 \times 20 \mathrm{~cm})$ connected by a central alley $(5 \times 15 \times 20 \mathrm{~cm})$ (middle neutral compartment). Two sliding doors separated the alley from the chambers. In each chamber two Plexiglas prisms with triangular bases $(5 \times 7 \times 19 \mathrm{~cm})$ were arranged to form different patterns (always covering the same surface of the chamber) and were used as conditioned stimuli. Two different metallic grids, 
one with large $(1 \mathrm{~cm})$ squares and the other with small $(0.5 \mathrm{~cm})$ circles were also used as conditioned stimuli. Two infrared photocells were present in each compartment and detected the presence and movements of animals using infrared light and communicated the information to a connected PC. Software (Imetronic, Pessac, France) analyzed rat movements within each compartment of the apparatus, measured the number of entries and the time rats spent in each compartment.

\subsubsection{Procedure}

The experiments consisted of 4 phases: habituation, pretest, a conditioning period, and a test phase. The time-course and pharmacology are presented in the following schematic:

A

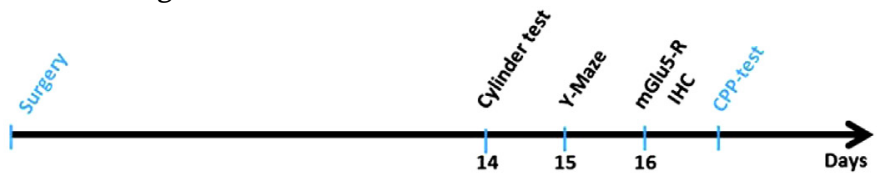

B

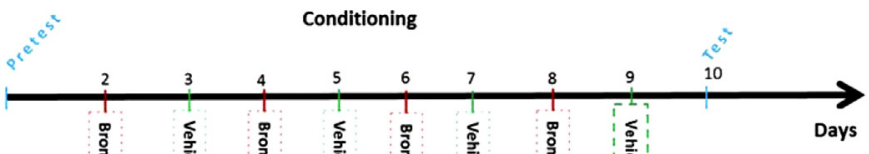

C

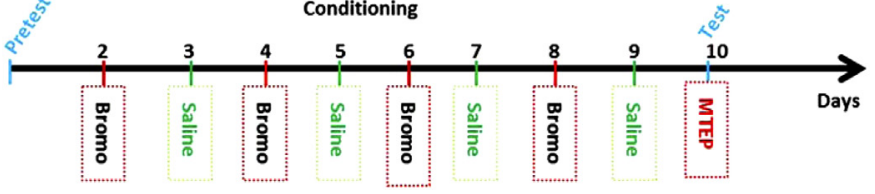

A:experimental time course; $B$ : CPP acquisition's group; $C$ : CPP expression's group.

Bromo: Bromocriptine, MTEP: mGlu5 receptor negative allosteric modulator, Vehicle:

Bromocriptine solvent, Saline: MTEP solvent.

\subsubsection{Habituation}

Rats were handled for 5 days and during the last two days they received an injection of a vehicle solution (drug-free solution).

\subsubsection{Pretest}

The next day, the animals were placed in the central alley. During the pretest, that took place under drug-free conditions, animals received only vehicle and were free to explore the entire apparatus for $15 \mathrm{~min}$. The time spent in each compartment during this $15 \mathrm{~min}$ session was measured. Were excluded from the experiment rats that spent more than $70 \%$ in one compartment.

\subsubsection{Conditioning period}

The animals were conditioned in the compartment in which they spent less time in the pretest session. It consisted of one session of 30 min per day during 8 days. Each animal had one session with a drug injection alternated the second day with an injection of a vehicle solution. The animals were divided into two groups according to a counterbalanced design. During a single session one animal group received the drug tested, while the other received only the vehicle solution. This procedure was alternated on the other day. During place conditioning, the rats received four drugpaired sessions and four vehicle paired sessions. This procedure ruled out that place preference would result from response bias.

\subsubsection{Test}

The next day, the animals were introduced into the apparatus by placing them in the central alley and did not receive any drug or vehicle for the CPP aquisition's group or MTEP injection for the CPP expression's group. The time spent in each compartment during a 15 min session was measured.

Data were presented as means of individual differences between times spent in the drug-paired compartment during the pretest phase and during the testing day. Positive values reflected a conditioned place preference (CPP) and negative values reflected a conditioned place aversion (CPA). A significant difference between the time spent in the drug-paired compartment during the pretest phase and the time spent in this compartment during the testing day was considered as a CPP or a CPA. 

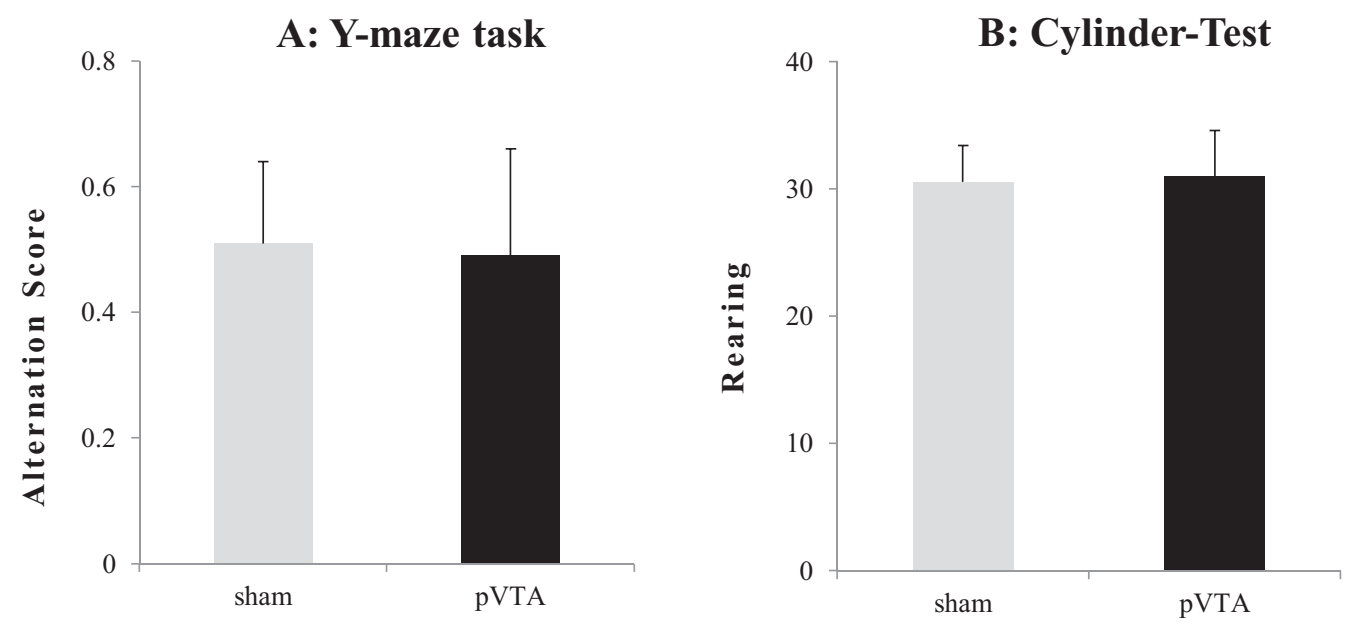

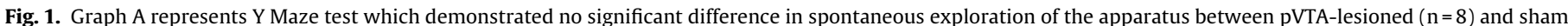

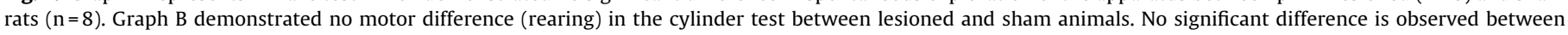
pVTA-lesioned $(n=10)$ and sham $(n=10)$ animals.

Image software. For each animal group, data were the total number of cells in the section ( $n=12$ per animal) of the pVTA, and were expressed as the percentage of the number of cell bodies measured for the shams (mean $\pm S D$ ).

\subsection{In vivo proton magnetic resonance spectroscopy (1H-MRS)}

1H-MRS scans were performed at $11.7 \mathrm{~T}$ on a Bruker BioSpec 117/16 Ultra Shielded Refrigerated system [7,8]. Animals were secured with two earpieces and a bite bar in a holder. They were kept anesthetized with 1-2.4\% isoflurane combined with a mixture of air and 02 (70\% and 30\%, respectively; $1000 \mathrm{~mL} / \mathrm{min}$ ). A circular polarized $1 \mathrm{H}$ rat brain radiofrequency coil used for excitation and signal reception was fixed on the holder, then all the system was placed at the isocenter of the magnet. Breathing and temperature parameters were monitored (Small Animal Instruments Inc.) along the session and temperature was maintained at $37.0^{\circ} \mathrm{C}$ by warm air system. Anesthesia was adjusted according to the respiratory rate. For positioning of the spectroscopic voxels in the PFC and the NAc, T2-weighted multislice images were acquired using a fast spin echo technique with a field of view of $35 \times 35 \mathrm{~mm} 2 ; 256 \times 256$ data matrix; $1 \mathrm{~mm}$ slice thickness; effective $\mathrm{TE}=15.72 \mathrm{~ms} ; \mathrm{TR}=2500 \mathrm{~ms}$ and number of averages $=2$ leading to a total experimental time of $5.20 \mathrm{~min}$. Localized $1 \mathrm{H}$-MRS spectra were acquired in a $20 \mu \mathrm{L}$ $(2.5 \times 4.0 \times 2.0 \mathrm{~mm})$ voxel of interest (VOI) fromthe PFC and in $8 \mu \mathrm{L}$ $(2 \times 2 \times 2 \mathrm{~mm}$ ) VOI from the NAc (Fig. 1). The middle of the PFC voxel was positioned $4.2 \mathrm{~mm}$ anterior from the bregma, on the bregma and $3.0 \mathrm{~mm}$ from the skull surface according to the Paxinos and Watson atlas. Similarly, the middle of the NAc voxel was positioned $2.2 \mathrm{~mm}$ anterior and $1.0 \mathrm{~mm}$ left or right (position to the right or left was alternately randomly defined) from the bregma and $6.5 \mathrm{~mm}$ from the skull surface.

The standard point-resolved spectroscopy (PRESS) sequence was used for spectra acquisition with $\mathrm{TE}=16 \mathrm{~ms}$, $\mathrm{TR}=4000 \mathrm{~ms}$ and an acquisition spectral width of $5000 \mathrm{~Hz}$, combined with VAPOR water suppression module consisting of variable-power RF pulses with optimized relaxation delays [47]. Magnetic field homogeneity was adjusted automatically using $1 \mathrm{st}$ and 2 nd order shims and the half-height linewidth of the water signal was between 13.4 and $20.1 \mathrm{~Hz}$ for all animals and VOIs. Each spectrum corresponded to 512 and 1024 averaging scans for the PFC and the NAc, respectively. For quantification purpose, water spectra were acquired using same conditions as for the metabolite spectra but without water suppression and with 16 averaging scans. Experimental spectra were fitted with jMRUI software (version 5.2, http:// www.mrui.uab.es/mrui) using the time-domain semi-parametric algorithm AQSES, based on signals for a basis set of simulated metabolites. The metabolite basis set included: lactate (Lac), $\mathrm{N}$-acetylaspartate (NAA), total creatine (creatine and phosphocreatine; $\mathrm{tCr}$ ), total choline (glycerophosphocholine and phosphocholine; tCho), glutamate (Glu), glutamine (Gln), $\gamma$-aminobutyric acid (GABA), taurine (Tau) and myo-inositol (Myo-Ins). It also included a simulated signal of macromolecules and lipids (MM). The intensity of the water signal obtained from non-suppressed water spectrum was used as an internal reference. For metabolite concentration measurements, we assumed water content of $80 \%$ and a water molarity of $43.3 \mathrm{M}$.

Concentrations were not corrected for $\mathrm{T} 1$ and $\mathrm{T} 2$ relaxation time effects because, under our experimental conditions (long TR and short TE), their effects are negligible. The reliability of metabolite quantification was assessed from the average Cramer-Rao lower bounds (CRLB) calculated by jMRUI. Only results with a CRLB $\leq 30 \%$ were included.

\subsubsection{Statistical analysis}

The body weight, motor performance and $\mathrm{TH}$ expression were compared by Student's $t$-test. For the CPP data, differences between pretest and test values for the drug-paired compartment were analyzed by Student's $t$-test for independent samples. Significance was considered at $\mathrm{p}<0.05$ level. Next, results of CPP for each tested drug were compared by a two-way ANOVA (group and drug treatments). The total number of TH immunoreactive cells were compared by a one-way ANOVA (group), followed by a post-hoc StudentNewmane-Keuls test if ANOVA was significant $(p<0.05)$. Analyses were made with Statistica software (StatSoft France, MaisonsAlfort).

For in vivo proton magnetic resonance spectroscopy, the size of the samples $(\mathrm{n})$ indicated in the figures refers to number of rats. Data are expressed as mean \pm SEM. Statistical analysis was performed in Statistica (version 7.1; Stat Soft, Maisons-Alfort, France) using the Student $t$-test. The p value for significance was set at 0.05 .

\section{Results}

\subsection{Learning and exploration}

Spontaneous exploration/spatial memory were investigated to study the effect of pVTA-lesion in this behavior. There was no 

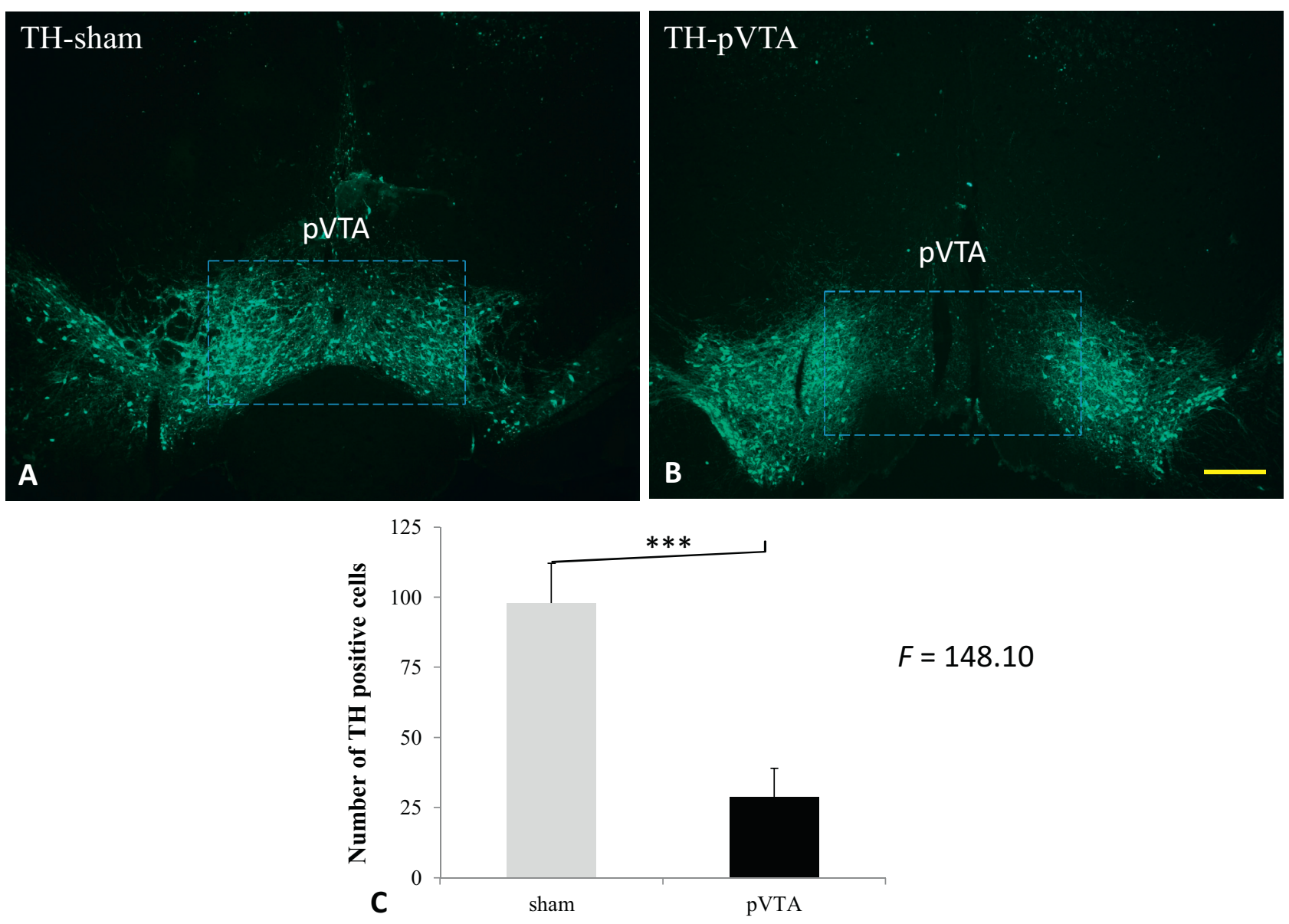

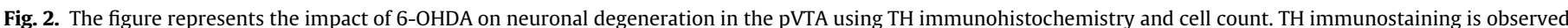

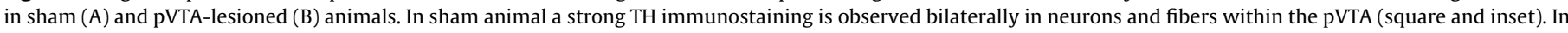

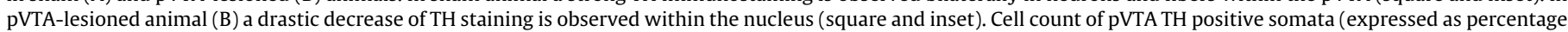

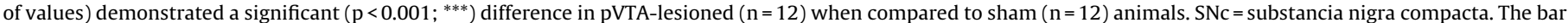
represents $200 \mu \mathrm{m}$.

significant difference in the spontaneous exploration/spatial memory in the Y Maze field between pVTA-lesioned $(n=12)$ and sham $(\mathrm{n}=11)$ rats. Both groups explored similarly the apparatus (Fig. 1A).

\subsection{Motor performance}

Locomotor impairment was investigated in order to explore the pVTA lesion effect on motor performance using the cylinder test. There was no significant score difference between pVTA-lesioned $(\mathrm{n}=12)$ and sham $(\mathrm{n}=11)$ groups (Fig. 1B).

Both Y maze and cylinder tests showed that pVTA lesion did not have any effect on motor performance and apparatus exploration in pVTA-lesioned group compared to sham rats.

\subsection{Tyrosine hydroxylase staining}

*At the conclusion of behavioral studies the labelling of tyrosine hydroxylase (Fig. 2A-C) was explored in both the pVTA-lesioned and compared to the sham groups in order to explore the impact of 6-OHDA toxin in the lesion of the pVTA. Tyrosine hydroxylase staining was observed in somata and processes in the pVTA. There was a general drastic decrease in the TH staining and in the number of positive cells in the pVTA-lesioned $(n=8)$ animals (Fig. 2B, inset) when compared to sham $(n=7)$ (Fig. $2 A$, inset) groups. Cell bodies count demonstrated a significant $\left(\mathrm{p}<0.001,{ }^{* * *}\right)$ cell loss differ- ence between 6-OHDA-lesioned and sham group (Fig. 3C). 6-OHDA injection induced almost $80 \%$ of neuronal cell loss in the pVTA.

\subsection{MTEP-effect on CPP}

The administration of bromocriptine, a D2R agonist, induced a significant CPP in the pVTA-lesioned rats (Fig. 3) as reported previously [39]. The MTEP was administered 30 min after the injection of bromocriptine. Thirty minutes later the rats were confined in the CPP apparatus. As observed in Fig. 3 the MTEP completely blocked the bromocriptine-induced CPP. It blocked both the acquisition (administration of MTEP during the conditioning phase, $n=12$ for bromocriptine-treated and $n=11$ for saline-treated pVTA-lesioned rats) and the expression (administration of MTEP during the day of the test, $\mathrm{n}=10$ for MTEP-treated rats and $\mathrm{n}=9$ for MTEP-non treated rats).

\section{5. mGlu5 receptor staining and cell count}

mGlu5 receptor staining was explored in the NAc of both pVTAlesioned $(n=8)$ and sham $(n=8)$ animals two weeks after the lesion (Fig. 4). A weak mGlu5 receptor staining was observed within the NAC in sham animals (Fig. $4 \mathrm{~A}$ and B). The staining was mostly observed within the shell (NAcSh) rather than the core (NAcC) subdivision. Within the shell, at high magnification, the mGlu5 receptor labelling was observed in neuronal cell bodies and 


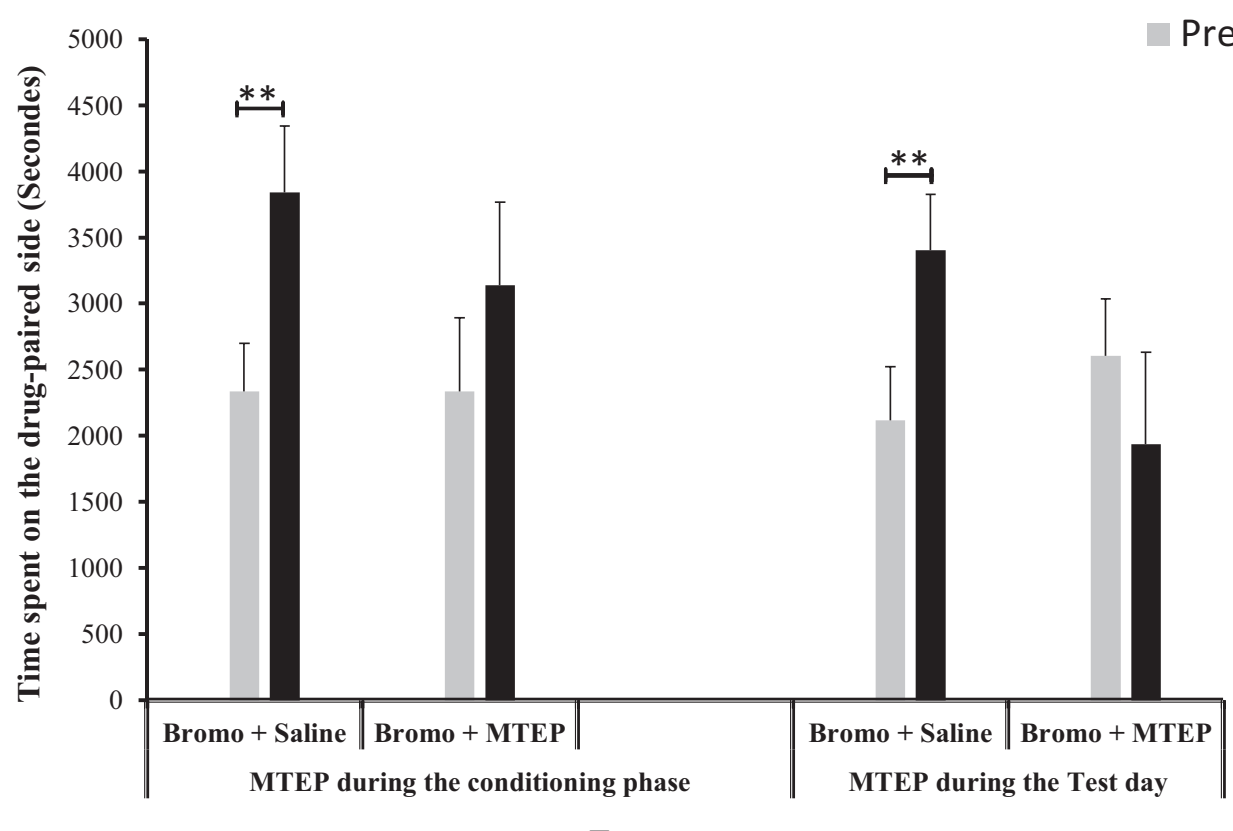

Treatments

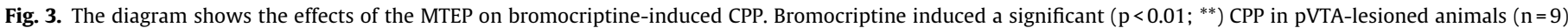

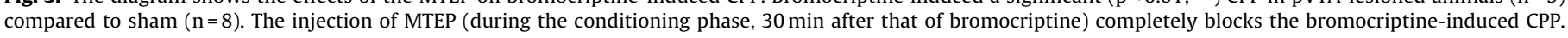
Similarly when the MTEP is administered only at the test day it also blocks the bromocriptine-induced CPP in pVTA-lesioned $(\mathrm{n}=7)$ but not in sham animals ( $\mathrm{n}=7$ ).

processes (Fig. 4B). However, there was a general increase in the mGlu5 receptor staining in the NAc of pVTA-lesioned animals (Fig. 4C and D). This increase was more prominent in the NAcSh (Fig. 4D) than in the NAcC subdivision. An increase in cell number and staining intensity could be observed in the NAcSh. Cell count (Fig. 5) revealed a significant increase of mGlu5 receptor positive neuronal cell number in the NAcSh of pVTA-lesioned in comparison to the sham.

\subsection{Measurement of absolute concentration of metabolites by in vivo $1 H-M R S$}

Representative in vivo $1 \mathrm{H}-\mathrm{MRS}$ spectra obtained in the PFC and the NAc are presented in Fig. 6. The majority of the metabolites had average CRLB lower than $20 \%$ in the PFC, with the exception of GABA (25-30\%) and Gln (20-25\%), and lower than 25\% in the NAC (Supplementary data).

Compared to the sham animals, concentrations of Glu and GABA in the NAC (Fig. 7A) were $23.1 \%$ higher $(17.39 \pm 1.66$ vs. $13.38 \pm 1.44 \mathrm{mM} ; \quad \mathrm{p}<0.05)$ and $50.8 \% \quad(1.89 \pm 0.35$ vs. $0.93 \pm 0.30 \mathrm{mM} ; \mathrm{p}<0.05)$, respectively in the 6-OHDA lesioned rats. The levels of Tau in 6-OHDA lesioned rats compared to sham were $26.1 \%$ lower $(12.24 \pm 0.61$ to $9.05 \pm 0.89 \mathrm{mM} ; \mathrm{p}<0.01)$ in the NAc. Concentrations of the other metabolites measured in the NAc were similar in both animal groups. In the PFC (Fig. 7B) of both 6-OHDA-lesioned and sham rat groups, metabolite levels were similar and the lesion did not affect the metabolite concentrations. In the PFC, the quantities of Tau in 6-OHDA lesioned rats compared to sham were also lower $(11.58 \pm 2.86$ to $10.05 \pm 2.18 \mathrm{mM})$, but the difference was not significant.

\section{Discussion}

The major results of the present study are: mGlu5 receptor negative allosteric modulator (MTEP) completely blocked the bromocriptine-induced CPP; it inhibited both the acquisition and the expression in bilateral pVTA-lesioned rats. The block of the CPP overlapped with a significant increase in both mGlu5 receptor protein expression (immunochemistry) and glutamate transmission (NMR spectroscopy) within the NAc of bilateral pVTA-lesioned rats.

The bilateral pVTA-lesion in combination with the administration of the D2R agonists were previously demonstrated to be implicated in the reinforcement [39,40]. The lesion induced an overexpression of D2R within the NAc shell which increased the efficacy of D2R agonist treatment during the CPP paradigm [39,40]. In the present study the effect of the mGlu5 receptor and its implication in the bromocriptine-induced reinforcement were explored. Thus MTEP completely inhibited the bromocriptine-induced CPP. It blocked both CPP acquisition (bromocriptine-induced conditioned learning) and expression (performance of behavior which reflects that of bromocriptine-conditioned learning). However, some discrepancies exist on the role of mGlu5 receptor in the conditioned rewarding effect, with one study showing a suppressive action on the acquisition and not on the expression using morphine [43] while another study reported an opposite effect using ethanol [33]. These discrepancies may be due to the pharmacological MTEP doses used, or to the different ways of administration (intra peritoneal versus intra-NAc). In the present study both CPP acquisition and expression were suppressed by MTEP.

Our data are in support of a reduction in the expression of CPP, conditioned locomotion, drug-seeking and self-administration by various drugs of abuse upon antagonizing mGlu5 receptor [20-22,31,48]. Likewise, mice lacking the mGlu5 receptor do not self-administer cocaine, demonstrating the essential role of this receptor in reinforcement behavior [10]. mGlu5 receptor effect is probably due, at the cellular level, to the facilitation of NMDA currents [36], long term potentiation [15]; and long term depression [17]. mGlu5 receptor knockout mice show deficits in NMDA currents; synaptic plasticity and learning $[27,35]$. In addition, mGluR1 group agonists increase the phosphorylation of the AMPA receptor subunits [1], hence facilitating glutamate transmission.

The PFC sends glutamatergic projections to the NAc that are selectively regulated by $\mathrm{D} 2 \mathrm{R}$ present at their synaptic terminals [18]. The administration of a D2R agonist attenuates PFC inputs, 


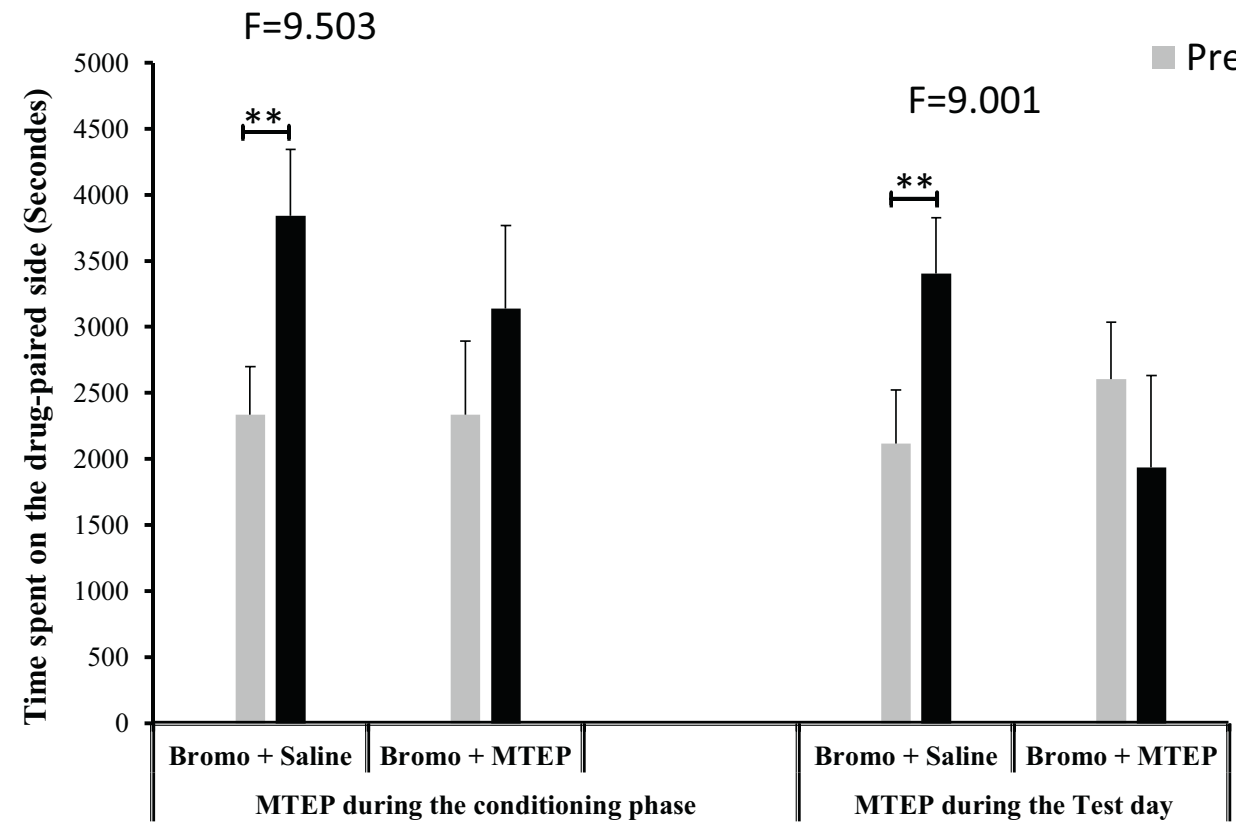

Treatments
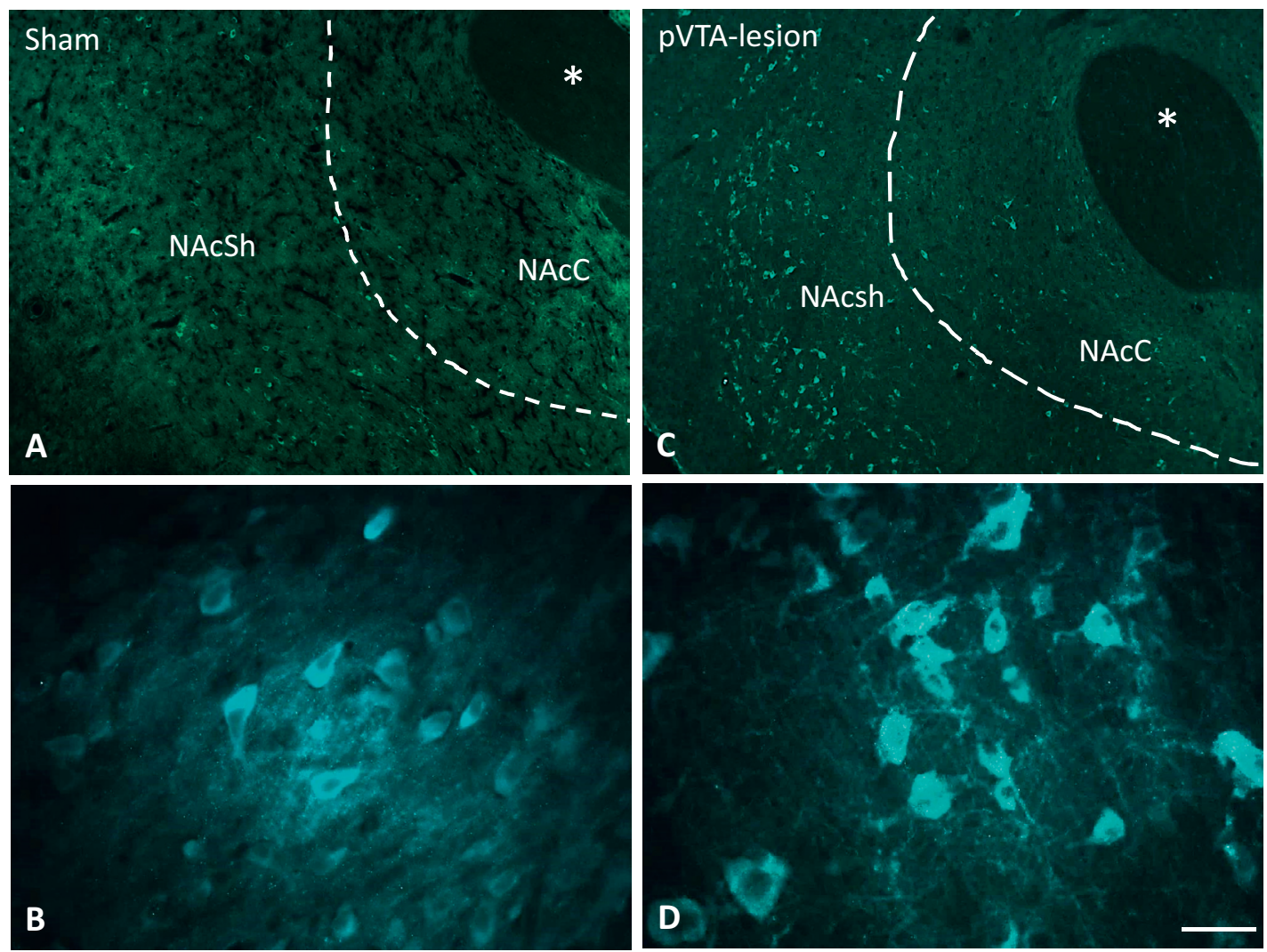

Fig. 4. The figure represents immunohistochemical analysis of mGlu5 receptor expression within the NAc of pVTA-lesioned $(n=8)$ and sham ( $n=8)$ animals. A weak mGlu5 receptor staining is observed within the NAc shell (NAcSh) and core (NAcC) subdivisions in sham animals (A). Cell body staining is more prominent in the shell than in the core of the nucleus. At a higher magnification (B) positive staining is observed within cell somata in the NAcSh. In pVTA-lesioned animals (C and D) a substantial increase in the mGlu5 receptor staining is observed in both NAc subdivisions but was more prominent in the NAcSh (C). At a high magnification intense staining is observed within cell somata and processes in the NAcSh (D). The bar represents $300 \mu \mathrm{m}$ in A and C; $80 \mu \mathrm{m}$ in B and D.

while the injection of D2R antagonist facilitates these inputs within the NAc [18]. This suggested that DA depletion within the NAc, such as in rats with pVTA lesion, will increase the glutamate secretion by PFC inputs to the NAc. This is supported by our data which showed an increase in glutamate in DA-depleted area and those of the literature reporting an hyperactive glutamate neurotransmission in basal ganglia depleted from DA [4-7,9,11,34]. The PFC results (NMR spectroscopy) confirm the specific and the localization of the DA- 


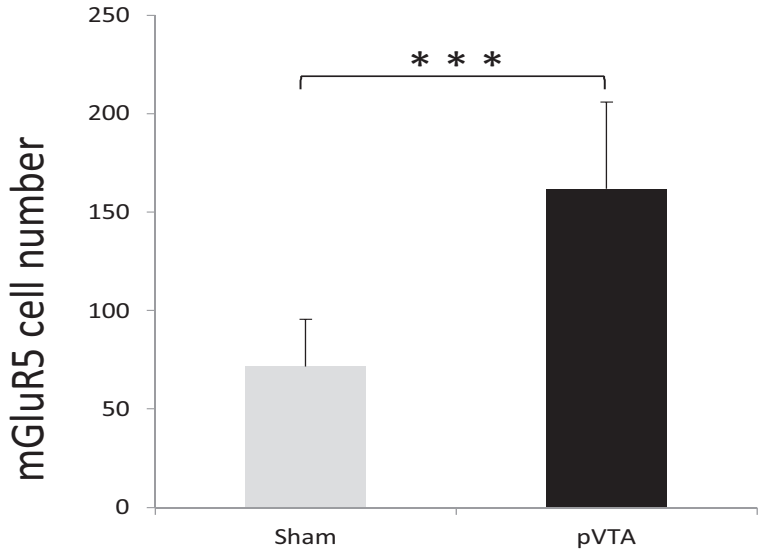

Fig. 5. Graph represent cell count of mGlu5 receptor positive somata within the NAcSh $(n=8)$ of lesioned and sham $(n=8)$ animals. There is a highly significant increase $\left(\mathrm{p}<0.001{ }^{* * *}\right)$ in mGlu5 receptor positive cell somata in the NAcSh of pVTA-lesioned animals when compared to sham.

depletion area since there was no significant metabolites change in this structure, which is known to receive DAergic inputs from the aVTA but not from the pVTA [24].

mGlu5 receptor overexpression was observed particularly in the NAc shell subregion and not in the core in pVTA-lesioned rats. The shell subregion is known to receive projections mostly from the pVTA while the core region is primarily innervated by the aVTA $[19,24]$. This suggested that mGlu5 receptor-increase targeted dopamine-depleted area of the NAc. Increases in mGlu5R density and striatal binding with selective mGlu5-receptor ligands are also observed in MPTP-lesioned macaques [44,45]. In support, the administration of cocaine reduced mGlu5 receptor surface expression in the NAc [14], and repetitive stimulations or epileptic activity increase grm5 gene (mGlu5 receptor) expression [28]. The mGlu5 receptor increase also highlighted glutamate hyperactivity within the DA-depleted NAc shell and not the DA non-depleted core area in addition to the possible activity upregulation of this receptor.

Another consequence of the prefrontal glutamatergic hyperactivity in the basal ganglia-DA-depleted is an increase in GABA neurotransmission [4-7,9,11,29,37]. This is also the case, in the present study, where NMR spectroscopy demonstrated a significant increase of GABA within the NAc. This GABA synthesis increase has been shown to be restricted to local GABAergic interneurons, and not the medial spiny cells [38]. This may suggested an hyperactivity of the prefrontal cortex inputs on the interneuron cells of the NAc shell in the present study.

\section{Conclusion}

This study demonstrated an essential role of mGlu5 receptor in the reinforcement. Antagonizing this receptor blocked the bromocriptine-induced reinforcement. It also suggests that
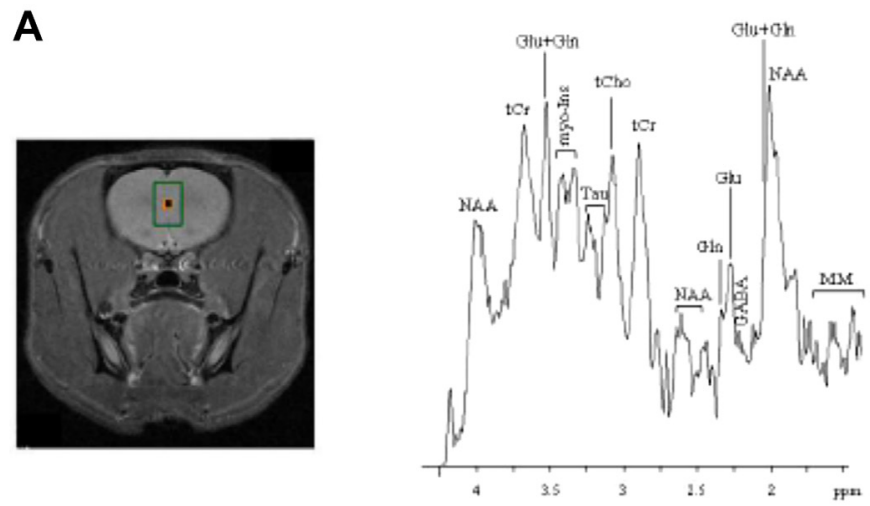

C
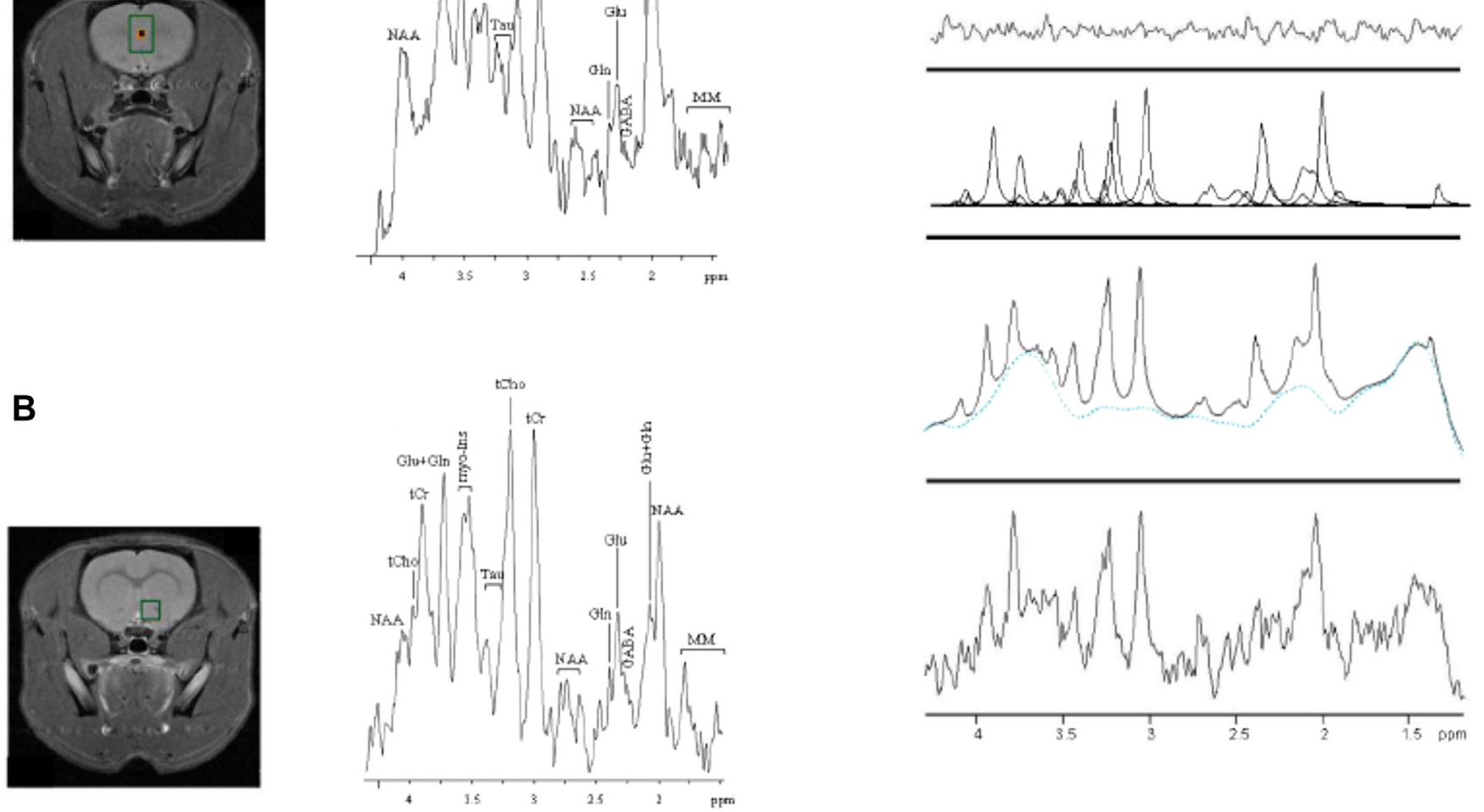

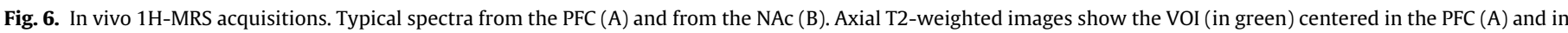

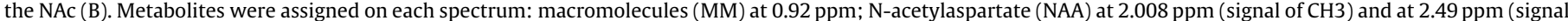

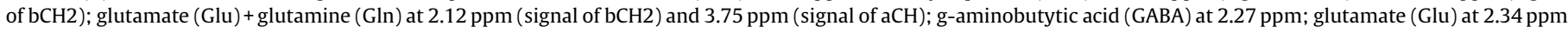

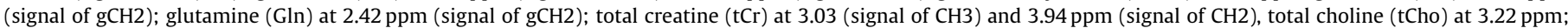

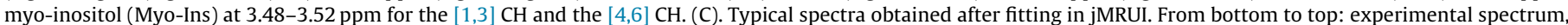

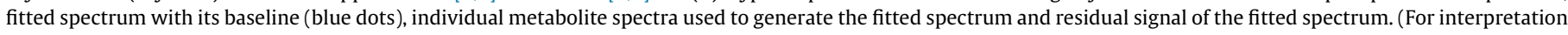
of the references to colour in this figure legend, the reader is referred to the web version of this article.) 
25,00
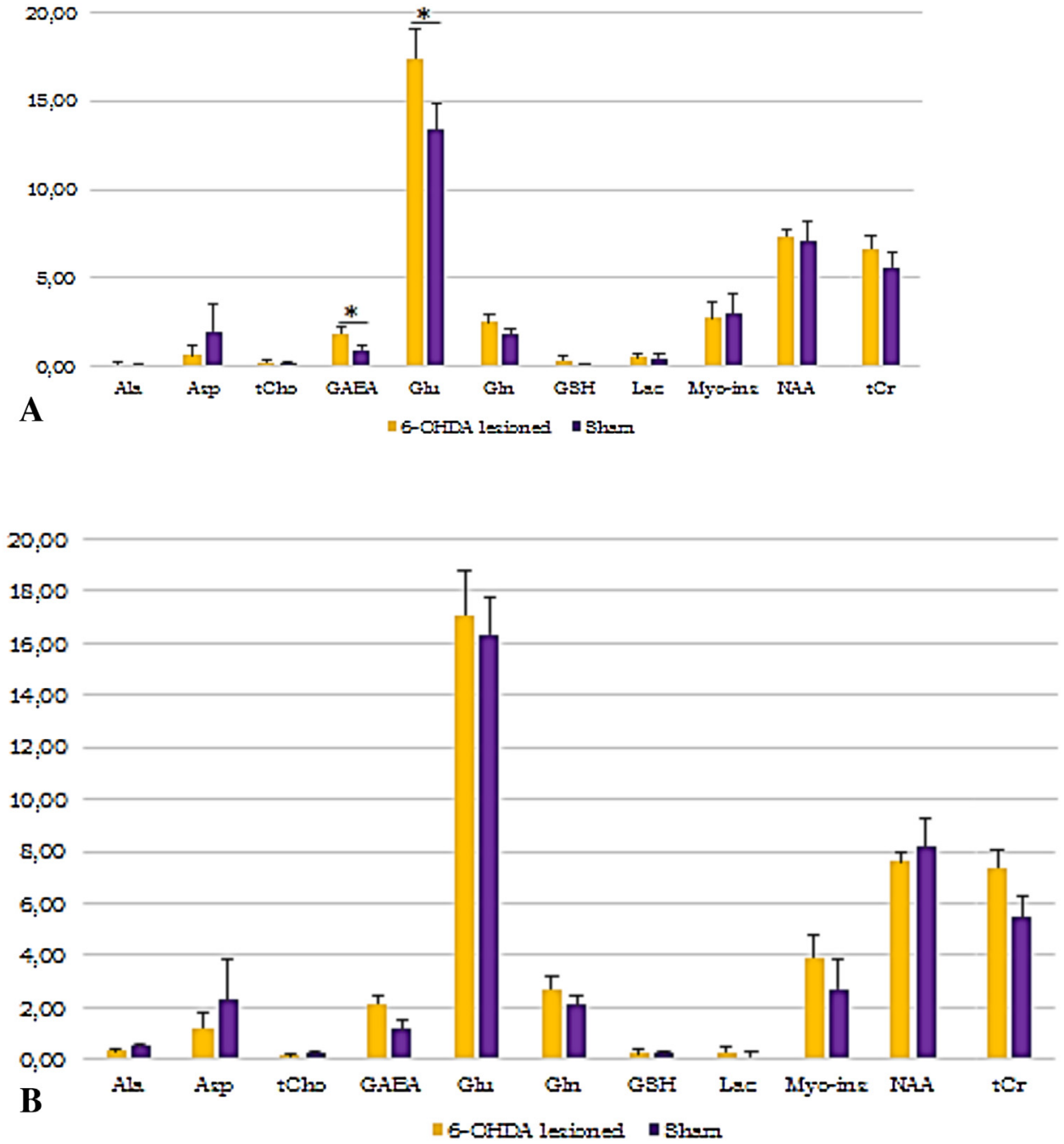

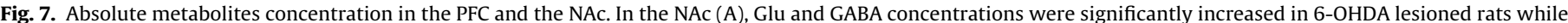

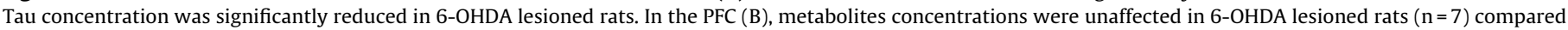
to $\operatorname{sham}(\mathrm{n}=6) .{ }^{*} \mathrm{p}<0.05 ;{ }^{* *} \mathrm{p}<0.01$.

targeting the mGlu5 receptor downstream cascade may help prevent DDS in Parkinson's disease while using DRT.

\section{Conflicts of interest}

Authors acknowledged that there are no conflicts of interest.

\section{Appendix A. Supplementary data}

Supplementary data associated with this article can be found, in the online version, at http://dx.doi.org/10.1016/j.bbr.2016.09.030.

\section{References}

[1] S.M. Ahn, E.S. Choe, Activation of group I metabotropic glutamate receptors increases serine phosphorylation of GluR1

alpha-amino-3-hydroxy-5-methylisoxazole-4-propionic acid receptors in the rat dorsal striatum, J. Pharmacol. Exp. Ther. 329 (2009) 1117-1126.

[2] J.J. Anderson, M.J. Bradbury, D.R. Giracello, D.F. Chapman, G. Holtz, J. Roppe, C. King, N.D. Cosford, M.A. Varney, In vivo receptor occupancy of mGlu5 receptor antagonists using the novel radioligand

[3H]3-methoxy-5-(pyridin-2-ylethynyl)pyridine), Eur. J. Pharmacol. 473 (2003) 35-40
[3] M. Amalric, Targeting metabotropic glutamate receptors (mGluRs) in Parkinson's disease, Curr. Opin. Pharmacol. 20 (2015) 29-34.

[4] P. Bagga, A.N. Chugani, K.S. Varadarajan, A.B. Patel, In vivo NMR studies of regional cerebral energetics in MPTP model of Parkinson's disease: recovery of cerebral metabolism with acute levodopa treatment, J. Neurochem. 127 (2013) 365-377.

[5] F. Blandini, G. Nappi, C. Tassorelli, E. Martignoni, Functional changes of the basal ganglia circuitry in Parkinson's disease, Prog. Neurobiol. 62 (2000) 63-88.

[6] D. Centonze, P. Calabresi, P. Giacomini, G. Bernardi, Neurophysiology of Parkinson's disease: from basic research to clinical correlates, Clin. Neurophysiol. 110 (1999) 2006-2013.

[7] C. Chassain, G. Bielicki, C. Carcenac, A.C. Ronsin, J.P. Renou, M. Savasta, F. Durif, Does MPTP intoxication in mice induce metabolite changes in the nucleus accumbens? A ${ }^{1} \mathrm{H}$ nuclear MRS study, NMR Biomed. 26 (2013) 336-347.

[8] C. Chassain, C. Melon, P. Salin, F. Vitale, S. Couraud, L. Durif Kerkerian-Le Goff, P. Gubellini, Metabolic, synaptic and behavioral impact of 5-week chronic deep brain stimulation in hemiparkinsonian rats, J. Neurochem. 136 (2016) 1004-1016.

[9] C. Chassain, G. Bielicki, E. Durand, S. Lolignier, F. Essafi, A. Traoré, F. Durif, Metabolic changes detected by proton magnetic resonance spectroscopy in vivo and in vitro in a murin model of Parkinson's disease, the MPTP-intoxicated mouse, J. Neurochem. 105 (2008) 874-882.

[10] M. Chiamulera, A. Epping-Jordan, C. Zocchi, C. Marcon, S. Cottiny, M. Tacconi, F. Corsi, F. Orzi, F. Conquet, Reinforcing and locomotor stimulant effects of cocaine are absent in mGluR5 null mutant mice, Nat. Neurosci. 4 (2001) 873-874. 
[11] N. Dehorter, C. Guigoni, C. Lopez, J. Hirsch, A. Eusebio, Y. Ben-Ari, C. Hammond, Dopamine-deprived striatal GABAergic interneurons burst and generate repetitive gigantic IPSCs in medium spiny neurons, J. Neurosci. 29 (2009) 7776-7787.

[12] A.H. Evans, A.P. Strafella, D. Weintraub, M. Stacy, Impulsive and compulsive behaviors in Parkinson's disease, Mov. Disord. 24 (2009) 1561-1570.

[13] S. Fenu, J. Wardas, M. Morelli, Impulse control disorders and dopamine dysregulation syndrome associated with dopamine agonist therapy in Parkinson's disease, Behav. Pharmacol. 20 (2009) 363-379.

[14] L. Fourgeaud, S. Mato, D. Bouchet, A. Hémar, P.F. Worley, O.J. Manzoni, A single in vivo exposure to cocaine abolishes endocannabinoid-mediated long-term depression in the nucleus accumbens, J. Neurosci. 24 (2004) 6939-6945.

[15] W. Francesconi, M. Cammalleri, P.P. Sanna, The metabotropic glutamate receptor 5 is necessary for late-phase long-term potentiation in the hippocampal CA1 region, Brain Res. 1022 (2004) 12-18.

[16] D.C. German, K. Manaye, W.K. Smith, D.J. Woodward, C.B. Saper, Midbrain dopaminergic cell loss in Parkinson's disease: computer visualization, Ann. Neurol. 26 (1989) 507e514.

[17] C.M. Gladding, S.M. Fitzjohn, E. Molnár, Metabotropic glutamate receptor-mediated long-term depression: molecular mechanisms, Pharmacol. Rev. 61 (2009) 395-412.

[18] Y. Goto, A.A. Grace, Dopaminergic modulation of limbic and cortical drive of nucleus accumbens in goal-directed behavior, Nat. Neurosci. 8 (2005) $805-812$.

[19] S.N. Haber, J.L. Fudge, N.R. McFarland, Striatonigrostriatal pathways in primates form an ascending spiral from the shell to the dorsolateral striatum, J. Neurosci. 20 (2000) 2369-2382.

[20] A.A. Herrold, R.M. Voigt, T.C. Napier, mGluR5 is necessary for maintenance of methamphetamine-induced associative learning, Eur. Neuropsychopharmacol. 23 (2013) 691-696.

[21] V. Herzig, W.J. Schmidt, Effects of MPEP on locomotion, sensitization and conditioned reward induced by cocaine or morphine, Neuropharmacology 47 (2004) 973-984.

[22] V. Herzig, E.M. Capuani, K.A. Kovar, W.J. Schmidt, Effects of MPEP on expression of food-, MDMA- or amphetamine-conditioned place preference in rats, Addict. Biol. 10 (2005) 243-249.

[23] J.P. Huston, M.A. Silva, B. Topic, C.P. Müller, what's conditioned in conditioned place preference? Trends Pharmacol. Sci. 34 (2013) 162-166.

[24] S. Ikemoto, Dopamine reward circuitry: two projection systems from the ventral midbrain to the nucleus accumbens-olfactory tubercle complex, Brain. Res. Rev. 56 (2007) 27-78.

[25] R. Ito, T.W. Robbins, B.J. Everitt, Differential control over cocaine-seeking behavior by nucleus accumbens core and shell, Nat. Neurosci. 7 (2004) 389-397.

[26] J. Jankovic, W. Poewe, Therapies in parkinson's disease, Curr. Opin. Neurol. 25 (2012) 433-447.

[27] Z. Jia, Y. Lu, J. Henderson, F. Taverna, C. Romano, W. Abramow-Newerly, J.M. Wojtowicz, J. Roder, Selective abolition of the NMDA component of long-term potentiation in mice lacking mGluR5, Learn. Mem. 5 (1998) 331-343.

[28] K. Kawaai, K. Tominaga-Yoshino, T. Urakubo, N. Taniguchi, Y. Kondoh, H. Tashiro, A. Ogura, T. Tashiro, Analysis of gene expression changes associated with long-lasting synaptic enhancement in hippocampal slice cultures after repetitive exposures to glutamate, J. Neurosci. Res. 88 (2010) 2911-2922.

[29] S.J. Kish, A. Rajput, J. Gilbert, L.J. Chang, K. Shannak, O. Hornykiewicz, Elevated g-aminobutyric acid level in striatal but not extrastriatal brain regions in Parkinson's disease: correlation with striatal dopamine loss, Ann. Neurol. 20 (1986) 26-31.

[30] G.F. Koob, N.D. Volkow, Neurocircuitry of addiction, Neuropsychopharmacology 35 (2010) 217-238

[31] J. Kotlinska, M. Bochenski, Pretreatment with group I metabotropic glutamate receptors antagonists attenuates lethality induced by acute cocaine overdose and expression of sensitization to hyperlocomotor effect of cocaine in mice, Neurotox. Res. 19 (2011) 23-30.

[32] M. Kuwajima, R.A. Hall, A. Aiba, Y. Smith, Subcellular and subsynaptic localization of group I metabotropic glutamate receptors in the monkey subthalamic nucleus, J. Comp. Neurol. 474 (2004) 589-602.
[33] J.Y. Lee, E.S. Choe, C.H. Yang, K.H. Choi, J.H. Cheong, C.G. Jang, J.W. Seo, S.S Yoon, The mGluR5 antagonist MPEP suppresses the expression and reinstatement, but not the acquisition, of the ethanol-conditioned place preference in mice, Pharmacol. Biochem. Behav. 140 (2016) 33-38.

[34] N. Lindefors, U. Ungerstedt, Bilateral regulation of glutamate tissue and extracellular levels in caudate-putamen by midbrain dopamine neurons, Neurosci. Lett. 115 (1990) 248-252.

[35] Y.M. Lu, Z. Jia, C. Janus, J.T. Henderson, R. Gerlai, J.M. Wojtowicz, J.C. Roder, Mice lacking metabotropic glutamate receptor 5 show impaired learning and reduced CA1 long-term potentiation (LTP) but normal CA3 LTP, J. Neurosci. 17 (1997) 5196-5205.

[36] G. Mannaioni, M.J. Marino, O. Valenti, S.F. Traynelis, P.J. Conn, Metabotropic glutamate receptors 1 and 5 differentially regulate CA1 pyramidal cell function, J. Neurosci. 21 (2001) 5925-5934.

[37] C. Melon, C. Chassain, G. Bielicki, J.P. Renou, L. Kerkerian-Le Goff, P. Salin, F. Durif, Progressive brain metabolic changes under deep brain stimulation of subthalamic nucleus in parkinsonian rats, J. Neurochem. 132 (2015) 703-712.

[38] C. Nitsch, R. Riesenberg, Synaptic reorganisation in the rat striatum after dopaminergic deafferentation: an ultrastructural study using glutamate decarboxylase immunocytochemistry, Synapse 19 (1995) 247-263.

[39] O. Ouachikh, W. Dieb, F. Durif, A. Hafidi, Differential behavioral reinforcement effects of dopamine receptor agonists in the rat with bilateral lesion of the posterior ventral tegmental area, Behav. Brain Res. 252 (2013) 24-31.

[40] O. Ouachikh, W. Dieb, F. Durif, A. Hafidi, Anterior ventral tegmental area dopaminergic neurons are not involved in the motivational effects of bromocriptine, pramipexole and cocaine in drug-free rats, Behav. Brain Res. 262 (2014) $1-7$.

[41] L. Pomierny-Chamioło, K. Rup, B. Pomierny, E. Niedzielska, P.W. Kalivas, P. Filip, Metabotropic glutamatergic receptors and their ligands in drug addiction, Pharmacol. Ther. 142 (2014) 281-305.

[42] O. Rascol, S. Fox, F. Gasparini, C. Kenney, T. Di Paolo, B. Gomez-Mancilla, Use of metabotropic glutamate 5-receptor antagonists for treatment of levodopa-induced dyskinesias, Parkinsonism Relat. Disord. 20 (2014) 947-956.

[43] N. Roohi, A. Sarihi, S. Shahidi, M. Zarei, A. Haghparast, Microinjection of the mGluR5 antagonist MTEP into the nucleus accumbens attenuates the acquisition but not expression of morphine-induced conditioned place preference in rats, Pharmacol. Biochem. Behav. 126 (2014) 109-115.

[44] P. Samadi, L. Gregoire, M. Morissette, F. Calon, A. Hadj Tahar, M. Dridi, N Beílanger, L.T. Meltzer, P.J. Beí dard, T. Di Paolo, mGluR5 metabotropic glutamate receptors and dyskinesias in MPTP monkeys, Neurobiol. Aging 29 (2008) 1040-1051.

[45] R. Sanchez-Pernaute, J.-Q. Wang, D. Kuruppu, L. Cao, W. Tueckmantel, A Kozikowski, O. Isacson, A.L. Brownell, Enhanced binding of metabotropic glutamate receptor type 5 (mGluR5) PET tracers in the brain of parkinsonian primates, Neuroimage 42 (2008) 248-251.

[46] S.S. Schwarz, W.J. Freed, Brain tissue transplantation in neonatal rats prevents a lesion-induced syndrome of adipsia, aphagia and akinesia, Exp. Brain. Res. 65 (1987) 449-454

[47] I. Tkác, P.G. Henry, P. Andersen, C.D. Keene, W.C. Low, R. Gruetter, Highly resolved in vivo $1 \mathrm{H}$ NMR spectroscopy of the mouse brain at 9.4 T, Magn. Reson. Med. 52 (2004) 478-484.

[48] M.M. Veeneman, H. Boleij, M.H. Broekhoven, E. Snoeren, M.G. Masip, ]. Cousijn, W. Spooren, L.J. Vanderschuren, Dissociable roles of mGlu5 and dopamine receptors in the rewarding and sensitizing properties of morphine and cocaine, Psychopharmacology (Berl.) 214 (2011) 863-876.

[49] V. Voon, A.R. Mehta, M. Hallett, Impulse control disorders in Parkinson's disease: recent advances, Curr. Opin. Neurol. 24 (2011) 324-330.

[50] D.1 Weintraub, J. Koester, M.N. Potenza, A.D. Siderowf, M. Stacy, V. Voon, J. Whetteckey, G.R. Wunderlich, A.E. Lang. Impulse control disorders in Parkinson disease: a cross-sectional study of 3090 patients, Arch. Neurol. 267 (2010) 589-595 


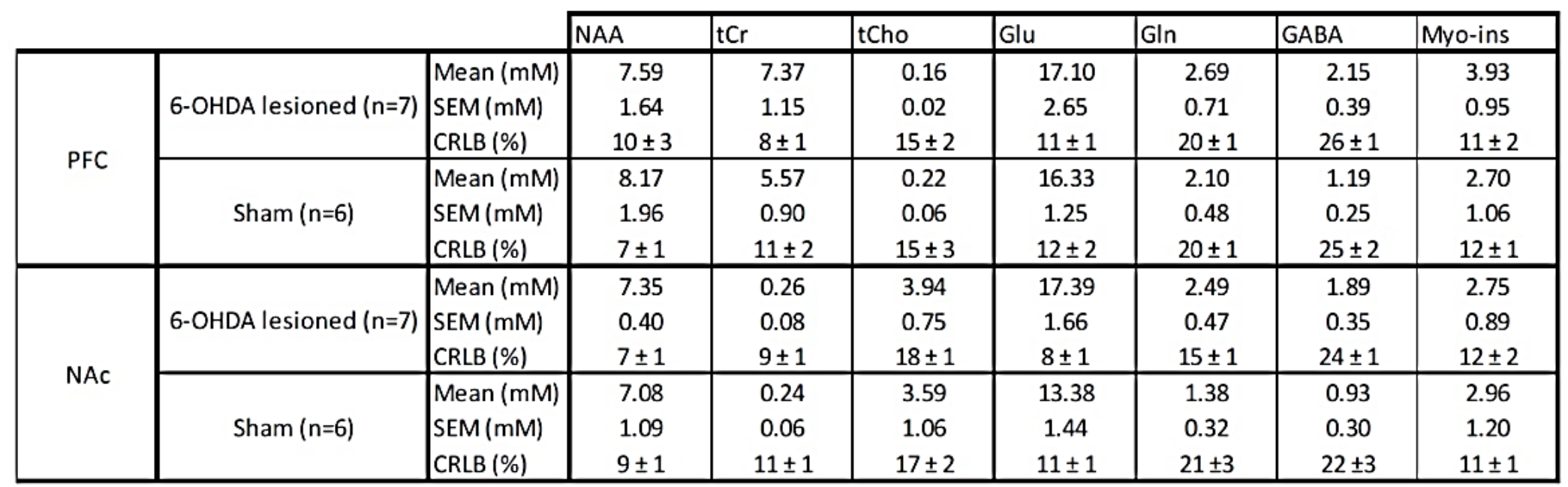

\section{Supplementary data}

